\title{
Endoscopic approach to juvenile nasopharyngeal angiofibroma: our experience at a tertiary care centre
}

\author{
A K Gupta, M G Rajiniganth, A K Gupta
}

\begin{abstract}
Objective: To evaluate the efficacy of endoscopic exposure and excision for juvenile nasopharyngeal angiofibroma.

Design: Prospective analysis of the outcomes of endoscopic removal of the angiofibroma at a tertiary care centre, using endoscopic and radiological parameters.

Subjects: Twenty-eight consecutive patients with angiofibroma were included. These patients underwent endonasal endoscopic excision of the lesion, following pre-operative computed tomography and digital subtraction angiography. Post-operative endoscopy and radiology were performed at six weeks to detect any residual lesion, and thereafter at six-monthly intervals to detect recurrence.

Results: Twenty-one patients ( 75 per cent) were new cases and seven patients ( 25 per cent) had recurrent tumour. Pre-operative embolisation was performed in 21 patients (75 per cent). An endoscopic endonasal approach was used to access the pterygopalatine fossa. The average blood loss was $228 \mathrm{ml}$. Residual lesion was noted in one patient (initially with recurrent stage II C pathology). The remaining 27 patients (initially with stage I, II A and II B pathology) were free of residual pathology or recurrence after a minimum follow-up period of 12 months.

Conclusion: Endoscopic exposure and excision of angiofibroma was found to be effective.
\end{abstract}

Key words: Angiofibroma; Nasopharynx; Surgery; Endoscopy

\section{Introduction}

Endoscopic sinus surgery is commonly indicated for chronic rhinosinusitis refractory to medical treatment. Endoscopic sinus surgery also has extended applications, firstly as an approach to the anterior cranial base, middle cranial base, orbit and pterygopalatine fossa, ${ }^{1,2}$ and secondly as a method of excision of juvenile nasopharyngeal angiofibroma. This excision technique is indicated for small to mediumsized tumours involving the posterior nasal cavity, nasopharyngeal, sphenoid sinus and pterygopalatine fossa. ${ }^{3}$ Many authors have reported their preliminary experiences of the removal of such tumours, either endoscopically or endoscope-assisted following conventional surgery. ${ }^{4-24}$ Endoscopic tumour removal can be assisted by electrocautery, ${ }^{3,22}$ laser, ${ }^{15,19}$ ultrasonic activated scalpel, ${ }^{17}$ image-guided surgery and frozen section pathological analysis. ${ }^{19}$

We report our experience of endoscopic exposure and excision of juvenile nasopharyngeal angiofibroma.

\section{Materials and methods}

This prospective study was carried out in the department of otolaryngology and head and neck surgery of the Postgraduate Institute of Medical Education and Research, Chandigarh, between June 2001 and January 2006.

All cases of diagnosed juvenile nasopharyngeal angiofibroma were considered for the study. Contrast-enhanced computed tomography (CT) of the paranasal sinuses was performed in all patients. Tumours were staged as per the Radkowski et al. system. $^{25}$

Thirty-eight cases of juvenile nasopharyngeal angiofibroma were detected. Tumours limited to the nose, nasopharynx, sphenoid sinus and pterygopalatine fossa, and those with limited infratemporal fossa extension, were included for endoscopic exposure and excision. Cases of both new and recurrent tumour were included in this study. Out of the 38 cases detected, 30 were included in this study. Angiographic studies were performed to delineate the vascular supply of the tumour, and as a prerequisite to embolisation.

After informed consent was obtained, all patients were surgically managed by an endonasal endoscopic technique. The amount of blood loss was assessed in all cases. Post-operatively, patients' nasal cavities were packed for three days, and they were given

From the Department of Otolaryngology and Head \& Neck Surgery, Postgraduate Institute of Medical Education \& Research, Chandigarh, India.

Accepted for publication: 8 October 2007. First published online 7 April 2008. 
intravenous antibiotics on an in-patient basis. Patients were assessed for any surgical complications.

All patients underwent paranasal sinus CT after six weeks to assess for residual pathology. Thereafter, patients were followed up every three months by endoscopic examination. A non-contrast CT of the paranasal sinuses was repeated six months after surgery to detect any recurrence. Patients were followed up for a minimum of 12 months to assess for recurrence.

Two of the cases were lost to follow up; hence, a final series of 28 cases is reported. Results were analysed using the unpaired $t$-test.

\section{Surgical procedure}

All the patients were operated upon using hypotensive general anaesthesia. Patients were positioned in the reverse Trendelenberg position, and $0^{\circ}, 30^{\circ}$ and $70^{\circ}$ endoscopes were used.

The extent of bony dissection was based on the radiological extent of the tumour. The steps required for exposure included ethmoidectomy, sphenoidotomy, middle meatus antrostomy and exposure of the pterygopalatine fossa. The anterior upper part of the perpendicular palatine bone was removed anteromedially and the posterior wall of the maxillary sinus was removed anterolaterally after a wide middle meatus antrostomy. The sphenopalatine foramen was widened anteriorly and the pterygopalatine fossa was visualised with $30^{\circ}$ and $70^{\circ}$ endoscopes. The periphery of the mucosa was cauterised and incised with a sickle knife. The dissection was performed using a blunt periosteal elevator in the submucosal plane. The inferior, medial and superior attachments of the tumour were released and the tumour was pushed downward. Lateral dissection was performed to push the tumour inferomedially into the nasopharynx. A Boyle-Davis mouth gag was applied, the soft palate was retracted and the tumour was grasped with a clamp and delivered transorally.

Nasal packing was performed in all patients. The pack was removed after 72 hours.

Patients received intravenous antibiotics for three days, and oral antibiotics for a further four days.

\section{Results}

The mean age of the patients was 14.75 years (range 10 to 20 years). All patients were male.

Out of 28 patients, seven cases ( 25 per cent) were recurrent following prior surgical excision of the tumour via an external approach. Six cases (21.43 per cent) had stage I tumour, 14 (50 per cent) had stage II A, six (21.43 per cent) had stage II B and two (7.14 per cent) had stage II C (Figures 1 to 3 ).

Digital subtraction angiography was performed in all cases. In 21 cases ( 75 per cent), the internal maxillary artery was shown to be the main vascular feeder and was embolised. The average blood loss for new and recurrent cases was $154 \pm 23 \mathrm{ml}$ and $390 \pm 32 \mathrm{ml}$, respectively. In cases involving embolisation, the blood loss was $168 \pm 24 \mathrm{ml}$; in those without embolisation, the blood loss was

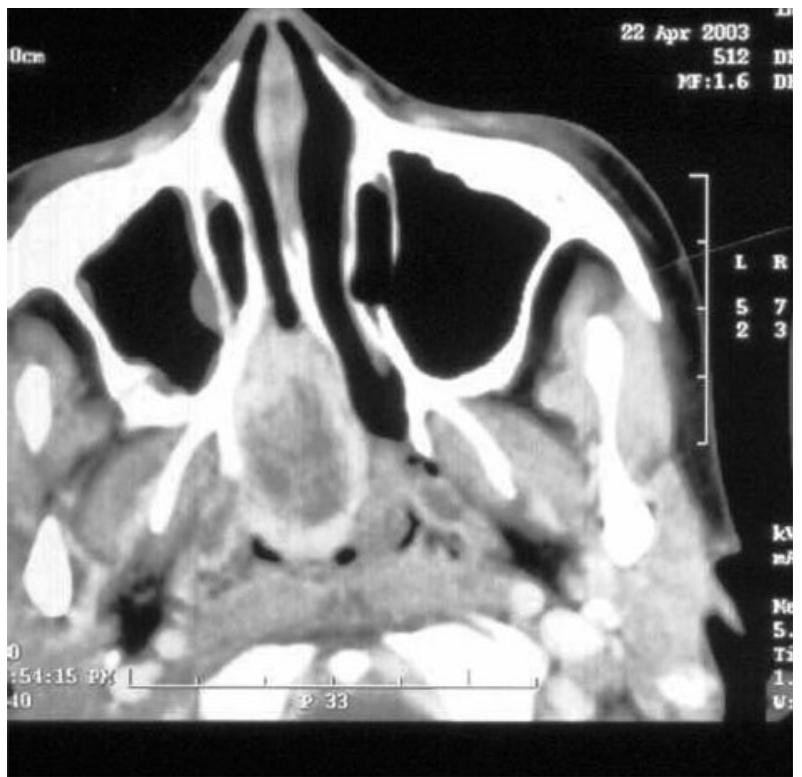

FIG. 1

Axial computed tomography scan showing stage I A tumour limited to the nose and nasopharynx.

$360 \pm 35 \mathrm{ml}$. Significantly more blood loss was noted in patients with recurrent tumours, no embolisation and transantral exposure (unpaired $t$-test; $p<0.05)$.

The tumour could be excised en bloc in all new cases and was delivered transorally.

Bleeding from the internal maxillary artery was noted in one patient (new case, unembolised) and was cauterised.

Residual lesion was noted in one case of recurrent stage II C pathology; this was subsequently excised via an external approach. In all other cases, no residual lesion was seen on six-week post-operative CT (Figure 4). One of the cases presented 10 months

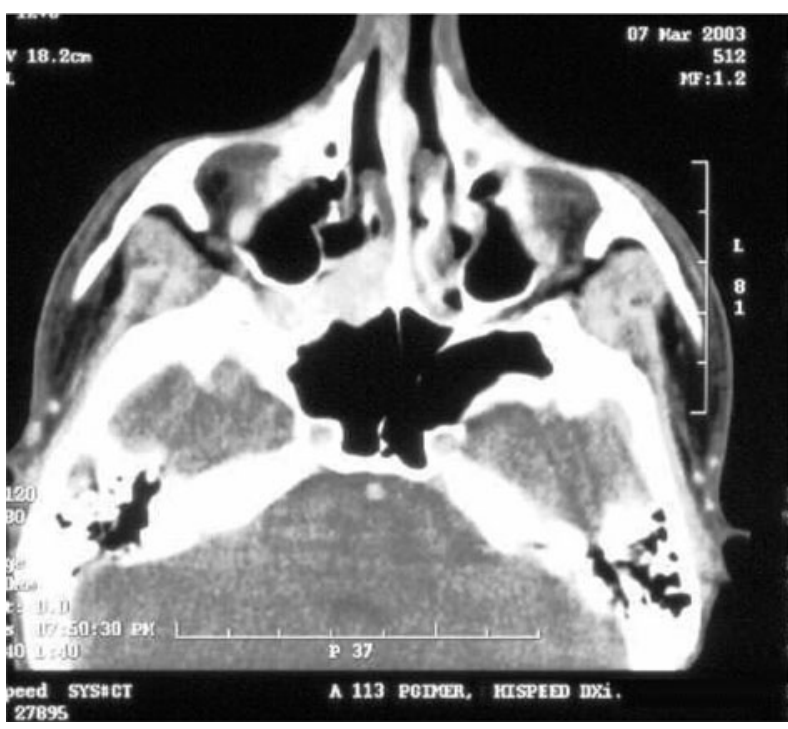

FIG. 2

Axial computed tomography scan showing stage II A tumour involving the nose and nasopharynx, with minimal extension into the pterygopalatine fossa. 


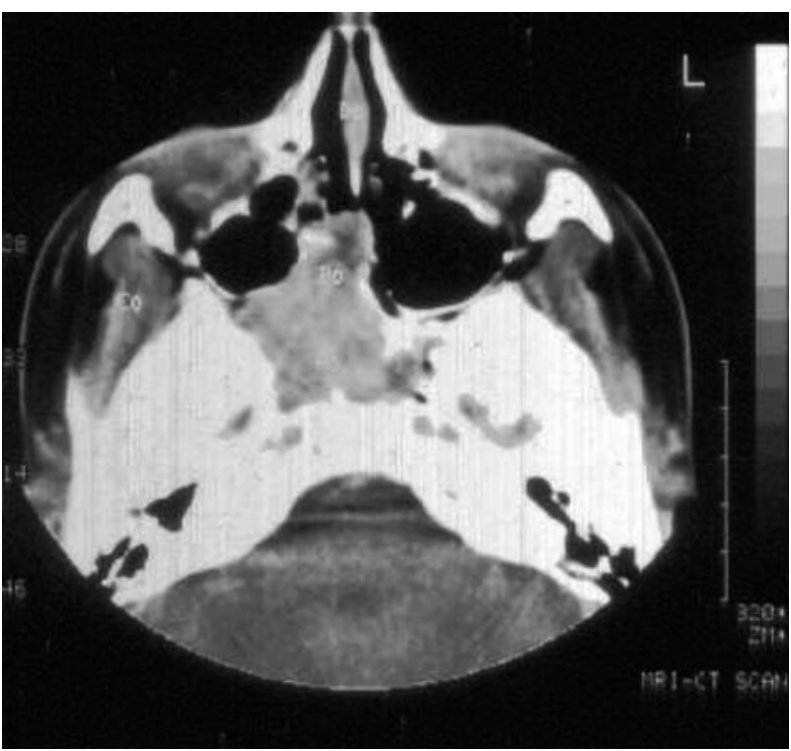

FIG. 3

Axial computed tomography scan showing stage II B tumour in the pterygopalatine fossa.

post-operatively with post-nasal discharge; a CT showed non-contrast hyperdense soft tissue in the sphenoid sinus, which was removed endoscopically and reported as an inflammatory polyp. Recurrence was not seen in any of the patients, following a minimum follow up of 12 months (range 12 to 65 months).

\section{Discussion}

Juvenile nasopharyngeal angiofibroma is a rare, benign, non-encapsulated tumour arising from the superior margin of the sphenopalatine foramen or the pterygopalatine fossa at the aperature of the vidian canal. It has a high rate of recurrence. ${ }^{26-28}$

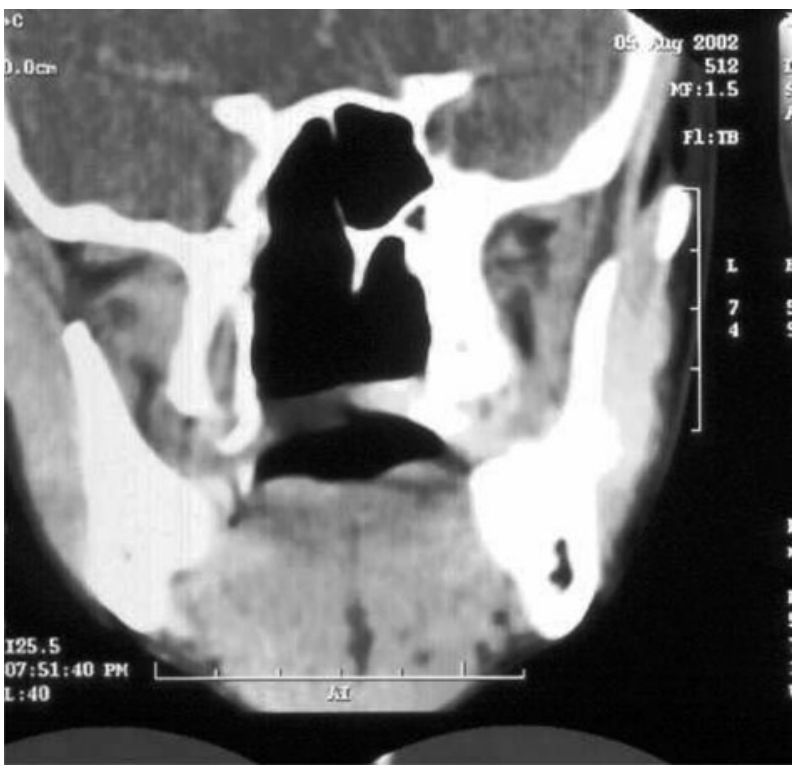

FIG. 4

Post-operative coronal computed tomography scan showing no tumour.
The tumour grows submucosally along the roof of the choana to reach the posterior border of the septum, and then expands further to present in the nasal cavity and nasopharynx. The tumour can further extend to the pterygopalatine fossa, infratemporal fossa, temporal fossa and orbit, and can also grow intracranially.

Surgical excision is the treatment of choice. The approach to the tumour can be transpalatal, transantral, lateral rhinotomy, midfacial degloving, maxillary swing, transzygomatic, transmandibular, transhyoid, or via craniofacial resection or the natural orifice, depending upon the tumour's extent.

The other modalities of treatment are radiotherapy, hormone therapy, cryotherapy, electrocoagulation, sclerotherapy and chemotherapy; these are considered as adjuncts to the surgical treatment of extensive tumour. ${ }^{29}$ Primary radiation therapy for angiofibroma, at doses of 3000-3500 cGy, has been considered in a few centres. ${ }^{27}$

Recent advancements in technology and techniques have made endoscopic excision of angiofibroma possible. Based on the experience of endoscopic sinus surgery and transnasal endoscopic vidian neurectomy, Kamel first suggested endoscopic transnasal surgery for angiofibroma in $1996 .{ }^{3}$ Subsequently, endoscopic tumour removal has been attempted by many authors and published as case reports or case series. ${ }^{4-24}$ The largest series was a retrospective study of 20 cases from six academic referral hospitals; the authors found the endoscopic approach to be the first choice for small to mediumsized angiofibromas. ${ }^{14}$ In their experience of 15 cases, Nicolai et al. found the endoscopic approach to be safe and effective. ${ }^{20}$ Endoscopic exposure and excision is considered to be the first choice of surgical approach in cases of limited angiofibroma involving the posterior part of the nasal cavity, nasopharynx, sphenoid sinus and pterygopalatine fossa.,14,20 Endoscopes can also be used to complement conventional surgery, enabling endoscope-assisted surgery for extensive lesions. ${ }^{12}$

Pre-operative assessment plays a major role in endoscopic exposure and excision of angiofibroma. Imaging is of paramount importance in the diagnosis, accurate estimation of extent and assessment of vascular supply. We found CT to be the radiological method of choice. Coronal plane views help to give better endoscopic orientation, and axial plane views give valuable information about the lateral extent of disease ${ }^{30}$. Digital subtraction angiography is best indicated for pre-operative endovascular embolisation, which reduces perioperative blood loss and improves the chances of complete tumour excision. ${ }^{28}$

We performed endonasal endoscopic excision of the tumour in all cases. The internal maxillary artery can be either clipped ${ }^{20}$ or diathermised. ${ }^{14}$ Endoscopic tumour removal in the infratemporal, parapharyngeal and pterygomaxillary regions can be supplemented with sublabial and buccolabial incisions. ${ }^{19}$ The tumour should be excised in the submucosal and subperiosteal planes, displaced and then finally delivered either transnasally or transorally. 

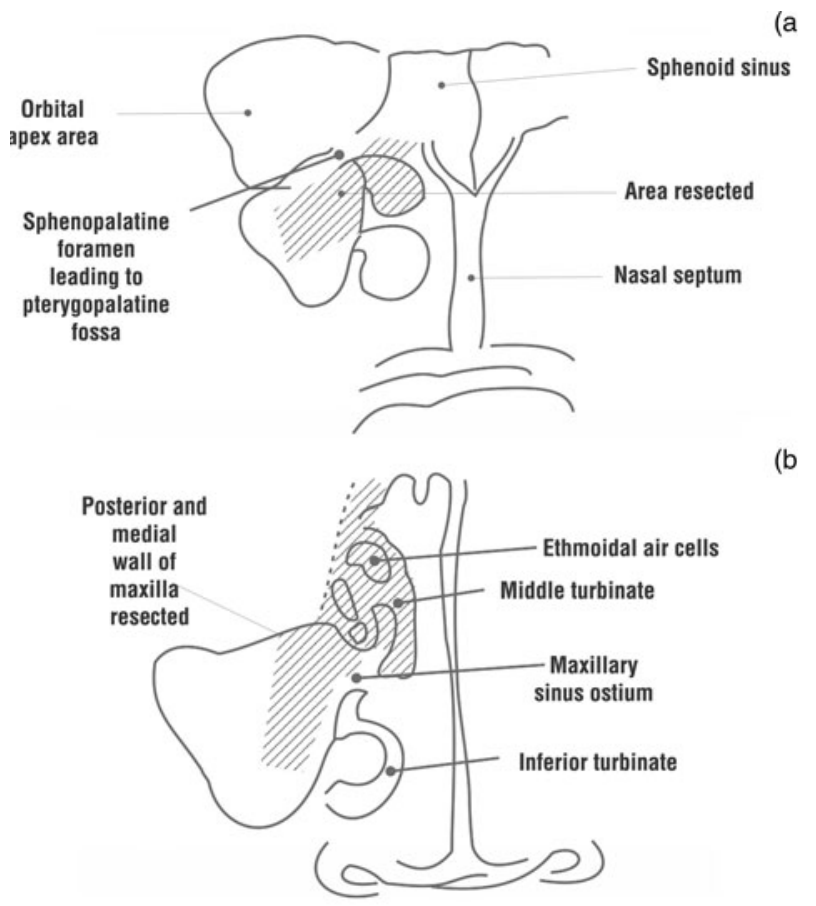

$\square$ Area resescted endoscopically

FIG. 5

Areas of endoscopic dissection. (a) Posterior part of the middle turbinate and posteromedial wall of maxilla resected shown in the shaded area; (b) Middle turbinate and ethmoidal air cells resected and wide midddle antrostomy done shown as shaded area.

In our cases, the order of tumour dissection was medial, superior lateral and then posterior. This order of dissection had the advantage of reduced bleeding.

In our series, all 21 new tumours were delivered transorally. In recurrent cases, there was extensive fibrosis; a clear margin could not be distinguished, and the tumour was excised transnasally in piecemeal fashion. En bloc excision has been attempted by most authors in one or two parts. In their series of five patients, Mair et al. excised tumours piecemeal with a microdebrider, after devitalising with a Neodymium yttrium aluminium garnet laser. ${ }^{19}$ We feel that new tumours can be excised en bloc by blunt dissection, and that recurrent tumours can be excised with the help of a laser, microdebrider, image-guidance system and frozen section pathological analysis.

Surgical management of angiofibroma can be complicated by haemorrhage and the persistence of residual lesion. These complications are always reduced if the tumour is extirpated with its roots.

The ideal surgical approach should enable direct access to the origin and extension of the tumour. The transpalatal approach has been recommended for lesions of less than $5 \mathrm{~cm}$, but it gives exposure to only the inferior surface, without any direct visualisation of the superior attachment. The lateral rhinotomy and other transfacial approaches give excellent exposure of the roots and extension of the tumour, but leave a facial scar. The endoscopic approach has the distinct advantage of direct access to the nasopharynx, sphenopalatine foramen, pterygopalatine fossa, sphenoid sinus and base of the pterygoid, without any facial scar. The endoscopic approach also has the advantages of reduced bleeding and lower incidence of residual lesion. In addition, this approach has the advantages of reduced morbidity, due to shorter hospitalisation, and avoidance of the problems of open surgery (i.e. epiphora, dysaesthesia, pain and the possible effects of facial growth).

- Endoscopic excision of juvenile nasopharyngeal angiofibroma is one of the extended applications of endoscopic sinus surgery

- This paper presents a prospective analysis of the outcomes of endoscopic removal of such angiofibroma at a tertiary care centre, using endoscopic and radiological parameters in 28 consecutive patients

- The endoscopic approach has the distinct advantage of enabling direct access to the nasopharynx, sphenopalatine foramen, pterygopalatine fossa, sphenoid sinus and base of the pterygoid, without producing a facial scar

- The endoscopic approach also has the advantages of reduced bleeding and a lower incidence of residual disease

Recurrence is a conspicuous feature of the natural history of juvenile nasopharyngeal angiofibroma, and has been related to the tumour extent and the involvement of such critical areas as the infratemporal fossa, sphenoid sinus, base of the pterygoid, clivus, medial aspect of the cavernous sinus, foramen lacerum and anterior fossa. ${ }^{26}$ The recurrence rate is higher for stage III than for stage I and II tumours. The residual rate after endoscopic procedure is 2.98 per cent (range 0-10 per cent). The usual sites of residual lesion after endoscopic surgery are the apex of the orbit, the interpterygoid fossa and around the cavernous sinus. The recurrence rate after endoscopic procedures has been reported as 9.32 per cent (range 0-30 per cent). Recurrence has been reported from various sites, including the nasopharynx, sphenoid sinus and clivus, commonly in extensive lesions. ${ }^{26} \mathrm{In}$ our series, residual lesion was seen in one case, and no case suffered recurrence over a follow-up period of 12 months (range 12-65 months).

\section{Conclusion}

Endoscopic exposure and excision of juvenile nasopharyngeal angiofibroma can be considered as a standard approach for limited lesions. This procedure should preferably be performed by an expert endoscopic rhinologist.

\section{References}

1 Davidson TM, Stearns G. Extended indications for endoscopic sinus surgery. Ear Nose Throat J 1994;73:467-468 
2 Alfieri A, Jho HD, Schettino R, Tschabitscher M. Endoscopic endonasal approach to the pterygopalatine fossa: anatomic study. Neurosurgery 2003;52:374-9

3 Kamel RH. Transnasal endoscopic surgery in juvenile nasopharyngeal angiofibroma. J Laryngol Otol 1996;110: $962-8$

4 Tseng HZ, Chao WY. Transnasal endoscopic approach for juvenile nasopharyngeal angiofibroma. Am J Otolaryngol 1997; 18:151-4

5 Mitskavich MT, Carrau RL, Snyderman CH, Weissman JL, Fagan JJ. Intranasal endoscopic excision of a juvenile angiofibroma. Auris Nasus Larynx 1998;25:39-44

6 Han D, Chen X, Wang J. Endoscopic nasal surgery in treatment of nasopharyngeal angiofibroma [in English]. Zhonghua Er Bi Yan Hou Ke Za Zhi 1998;33:358-60

7 Bernal-Sprekelsen M, Vazquez AA, Pueyo J, Carbonell Casasus J. Endoscopic resection of juvenile nasopharyngeal fibromas [in German]. HNO 1998;46:172-4

8 Schick B, el Rahman el Tahan A, Brors D, Kahle G, Draf W. Experiences with endonasal surgery in angiofibroma. Rhinology 1999;37:80-5

9 Jorissen M, Eloy P, Rombaux P, Bachert C, Daele J. Endoscopic sinus surgery for juvenile nasopharyngeal angiofibroma [in English]. Acta Otorhinolaryngol Belg 2000;54 201-19

10 Sarria R, Capitan A, Sprekelsen C, Viviente E, Cuervo G, Ferran A. Endoscopic surgery of nasopharyngeal angiofibroma by double embolization [in Spanish]. Acta Otorrinolaringol Esp 2000;51:259-62

11 Newlands SD, Weymuller EA Jr. Endoscopic treatment of juvenile nasopharyngeal angiofibroma. Am J Rhinol 1999; 13:213-19

12 Carrau RL, Snyderman CH, Kassam AB, Jungreis CA. Endoscopic and endoscopic-assisted surgery for juvenile angiofibroma. Laryngoscope 2001;111:483-7

13 Khalifa MA. Endonasal endoscopic surgery for nasopharyngeal angiofibroma. Otolaryngol Head Neck Surg 2001; 124:336-7

14 Roger G, Tran Ba Huy P, Froehlich P, Van Den Abbeele T, Klossek JM, Serrano E et al. Exclusively endoscopic removal of juvenile nasopharyngeal angiofibroma: trends and limits. Arch Otolaryngol Head Neck Surg 2002;128: 928-35

15 Hazarika P, Nayak DR, Balakrishnan R, Raj G, Pillai S. Endoscopic and KTP laser-assisted surgery for juvenile nasopharyngeal angiofibroma. Am J Otolaryngol 2002;23: 282-6

16 Kumar A, Deka RC, Jha D. Endoscopic removal of localized angiofibroma. J Otolaryngol 2002;31:41-4

17 Ochi K, Watanabe S, Miyabe S. Endoscopic transnasal resection of a juvenile angiofibroma using an ultrasonically activated scalpel. ORL J Otorhinolaryngol Relat Spec 2002; 64:290-3

$18 \mathrm{Xu} \mathrm{H}$, Fan Z. Endoscopic treatment of nasopharyngeal angiofibroma. Lin Chuang Er Bi Yan Hou Ke Za Zhi 2003;17:659-60
19 Mair EA, Battiata A, Casler JD. Endoscopic laser-assisted excision of juvenile nasopharyngeal angiofibromas. Arch Otolaryngol Head Neck Surg 2003;129:454-9

20 Nicolai P, Berlucchi M, Tomenzoli D, Cappiello J, Trimarchi M, Maroldi R et al. Endoscopic surgery for juvenile angiofibroma: when and how. Laryngoscope 2003;113:775-82

21 Naraghi M, Kashfi A. Endoscopic resection of nasopharyngeal angiofibromas by combined transnasal and transoral routes. Am J Otolaryngol 2003;24:149-54

22 Onerci TM, Yucel OT, Ogretmenoglu O. Endoscopic surgery in treatment of juvenile nasopharyngeal angiofibroma. Int J Ped Otolaryngol 2003;67:1219-25

23 Wormald PJ, Van Hasselt A. Endoscopic removal of juvenile angiofibromas. Otolaryngol Head Neck Surg 2003;129. 684-91

24 Mann WJ, Jecker P, Amedee R. Juvenile angiofibroma: changing surgical concepts over the last 20 years. Laryngoscope 2004:114:291-3

25 Radkowski D, McGill T, Healy GB, Ohlms L, Jones DT. Angiofibroma. Changes in staging and treatment. Arch Otolaryngol Head Neck Surg 1996;122:122-9

26 Herman P, Lot G, Chapot R, Salvan D, Huy PT Long-term follow-up of juvenile nasopharyngeal angiofibromas: analysis of recurrences. Laryngoscope 1999;109: $140-7$

27 Cumming BJ, Blend R, Keane T, Fitzpatrick P, Beale F, Clark R et al. Primary radiation therapy for juvenile nasopharyngeal angiofibroma. Laryngoscope 1984;94: $1599-605$

28 Petruson K, Rodriguez-Catarino M, Petruson B, Finizia C. Juvenile nasopharyngeal angiofibroma: long-term results in preoperative embolized and non-embolized patients. Acta Otolaryngol 2002;122:96-100

29 Neel HB, Whicker JH, Devine KD, Weiland LH. Juvenile angiofibroma review of 120 cases. Am J Surg 1973;126: $547-56$

30 Lloyd G, Howard D, Phelps P, Cheesman A. Juvenile angiofibroma: the lessons of 20 years of modern imaging. J Laryngol Otol 1999;113:127-34

Address for correspondence:

Dr Ashok K Gupta,

Professor

Dept of Otolaryngology and Head \& Neck Surgery,

Postgraduate Institute of Medical Education \& Research, Chandigarh 160012, India.

Fax: +91 1722744401

E-mail: akgpgi@yahoo.com

Dr A K Gupta takes responsibility for the integrity of the content of the paper.

Competing interests: None declared 